Sc Velenko Milanović, pukovnik, dipl. inž. VP 4100, Novi Sad

\section{METODOLOGIJA ODREĐIVANJA ELEKTROENERGETSKOG BILANSA OPERACIJE}

UDC: $621.8 .037: 519.6]: 355.42 / 43$

Rezime:

Pored ubojnih i pogonskih sredstava, električna energija je treći bitan elemenat energije boja. Proračun i poznavanje elektroenergetskog bilansa jedinice podrazumeva odredivanje potreba za električnom energijom (izvorima, punjačima, ispravljačima, pretvaračima), omogućuje iznalaženje optimalnih rešenja pomoću raspoložive opreme i sredstava, a komandovanju obezbeđuje donošenje pravovremenih $i$ kvalitetnih odluka i predstavlja bitan faktor borbene gotovosti jedinice. Poznavanje elektroenergetskog bilansa omogućuje odredivanje autonomnosti jedinica, što je važno za planiranje i realizaciju odredenih zadataka $i$ aktivnosti. U ovom radu predstavljen je matematički model za određivanje elektroenergetskog bilansa bilo koje jedinice, za sve uslove i zadatke u kojima se može naći i koje može izvršavati. Bilans se može odrediti sa ili bez upotrebe informatičke opreme što mu obezbeduje široku i svenivojsku primenu.

Ključne reči: elektroenergetski bilans, matematički model, električna energija, hemijski izvori struje.

\title{
METHODOLOGY OF DETERMINING ELECTRIC ENERGY BALANCE OF OPERATIONS
}

Summary:

Besides explosives and propulsive devices, electric energy represents the third crucial element of battle energy. Calculation and understanding of electric energy balance of units imply determination of needs for electric energy (sources, chargers, transformers, converters), enable optimal solutions by the help of available equipment and in commanding they provide making timely and high-quality decisions thus representing an important factor of unit combat readiness. Furthermore, knowledge of electric energy balance provides unit autonomy, which is very important in planning and realisation of particular missions and activities. This paper presents a mathematical model for electric energy balance determination for any type of units, all circumstances and missions they may be involved in. The model is applicable with or without use of computers, thus providing its wide and all level-application.

Key words: electric energy balance, mathematical model, electric energy, chemical sources of electric energy.

\section{Uvod}

Brzi razvoj tehnike, a posebno elektrotehnike i elektronike, u poslednjim dekadama dvadesetog veka, imao je veliki uticaj na kvalitet i način naoružavanja i opremanja jedinica Vojske Srbije i Crne
Gore. Elektronika se sa složenih sistema (veze, radarskih, raketnih i drugih), ,preselila" do samog vojnika, radi poboljšanja njegove efikasnosti i zaštite u borbi. Primena elektronike postaje sve masovnija u naoružavanju i opremanju svih naših jedinica, bez obzira na rod, službu i 
namenu. Da bi naoružanje i oprema bili u neprekidnoj i potpunoj funkciji, neophodno je obezbediti neprekidno i kvalitetno napajanje električnom energijom. Autonomnost jedinica, kao jedan od osnovnih principa u izvršavanju borbenih i drugih zadataka, nužno nameće potrebu da se, pored planskog obezbeđenja ubojnim, pogonskim i drugim sredstvima, planira i realizuje i obezbeđenje električnom energijom. Da bi se taj zadatak kvalitetno realizovao, potrebno je odrediti elektroenergetski bilans svake jedinice.

Kao i sve druge potrebe, i potrebe za električnom energijom proračunavaju se po određenoj metodologiji za svaku jedinicu, odnosno, za izvršenje određenog mirnodopskog ili borbenog zadatka. U ovom radu prikazana je metodologija određivanja, odnosno, proračuna elektroenergetskog bilansa operacije.

Autonomne izvore električne energije čine:

- hemijski izvori (akumulatori i galvanski elementi),

- mehanički izvori naizmenične struje - elektroagregati,

- pretvarači električne energije,

- punjači akumulatora.

\section{Odredivanje elektroenergetskog bilansa}

Elektroenergetski bilans načelno se određuje za ZTJ i niže jedinice, a može se razmatrati i utvrđivati preko:

- taktičkih parametara (oblik oružane borbe, vid borbenih dejstava, borbeni uslovi, zemljište, vreme, vreme neposrednog učešća $u b / d$, dnevni intenzitet upotrebe potrošača električne energije, režim rada na prijemu-predaji, prioritet u elektroenergetskom obezbeđenju);
- parametara tehničkog obezbeđenja (zadržavanje jedinice u određenom rejonu u zoni ili van zone $b / d$, trajanje premeštanja u novi rejon, svijanja i razvijanja za rad, prikupljanja akumulatora, pripreme akumulatora za punjenje, dotura napunjenih akumulatora, zamene akumulatora u jedinicama);

- tehničkih parametara (vrsta, broj i autonomija potrošača električne energije, broj osnovnih i rezervnih akumulatora, napon i nominalni kapacitet, koeficijent realnog kapaciteta, struja punjenja, struja prijema i predaje kod radio-uređaja, vreme punjenja, vrsta punjača i koeficijent iskoristivosti, nepovratni gubici akumulatora, vrsta i broj galvanskih elemenata, vrsta i broj potrošača naizmenične struje, koeficijent jednovremenog rada svih uređaja - potrošača električne energije).

Obezbeđenje operacije električnom energijom mora, po obimu i kvalitetu, da odgovara složenosti i značaju primene i upotrebe sredstava u uslovima izvođenja operacije. Zbog toga se proračunavaju i definišu autonomni izvori električne energije koji će pokrivati potrebe jedinica u toku izvođenja operacije, uz obezbeđenje maksimalne borbene goto$\operatorname{vosti}\left(K_{g}=1\right)$.

Za proračun je potrebno poznavati i definisati sve navedene parametre, jer oni utiču na tok i rezultate proračuna.

Definisani parametri i početni uslovi uvode se u matematički model proračuna elektroenergetskog bilansa, koji definišu sledeće relacije:

- instalisana energija svih akumulatora (radnih i rezervnih):

$W_{i n}=\sum_{i=1}^{n} C_{i} U_{i} n_{i} \quad\left[W_{h}\right]$ 
gde je:

$C_{i}$ - nazivni kapacitet $i$-te vrste akumulatora,

$U_{i}$ - nazivni napon $i$-te vrste akumulatora, $n_{i}$ - broj akumulatora $i$-te vrste.

Za izračunavanje ove vrednosti potrebno je znati brojno stanje akumulatora u svim jedinicama i njihove nazivne podatke;

- električna energija potrebna za punjenje svih akumulatora $\mathrm{u}$ jedinici, iz punjača:

$$
W_{p}=\sum_{i=1}^{n} I_{p i} U_{p i} t_{p i} n_{i} \quad\left[W_{h}\right]
$$

gde je:

$I_{p i}$ - struja punjenja $i$-te vrste akumulatora, $U_{p i}$ - napon punjenja $i$-te vrste akumulatora,

$t_{p i}$ - vreme punjenja $i$-te vrste akumulatora,

$n_{i}$ - broj akumulatora $i$-te vrste.

Uzimajući u obzir srednji napon punjenja akumulatora, dolazi se do koeficijenata punjenja za olovne i alkalne akumulatore, $\alpha_{P b}=1,38$ i $\alpha_{A l}=1,61$, pa se njihovom primenom dobiju sledeće relacije: latore,

$W_{p}=\alpha_{P b} W_{P b}-$ za olovne akumutore;

$W_{p}=\alpha_{A l} W_{A l}-$ za alkalne akumula-

- električna energija punjenja po danu rata izračunava se po izrazu:

$W_{d}=\sum_{i=1}^{n} \frac{W_{p i}}{A_{i}} t_{r} \quad\left[W_{h / \text { danrata }}\right]$

gde je:

$W_{p i}$ - energija punjenja $i$-te vrste akumulatora (Wh),
$A_{p i}$ - autonomija rada $i$-te vrste akumulatora $(\mathrm{h})$,

$t_{r}$ - broj dana rata (neprekidno angažovanje sredstava u b/d) tr $=10-16 \mathrm{~h} /$ dan rata;

- autonomija rada elektroničkih uređaja koji su napajani iz akumulatora za sredstva veze:

$$
A=\frac{n C_{s t v}(1 m)}{m\left(I_{\text {pred }} f_{\text {pred }}+I_{p r i j} f_{p r i j}\right)}
$$

gde je:

$n$ - broj kompleta akumulatora koji idu uz TMS, $C_{s t v}$ - stvarni kapacitet, $m$ - odnos vremena predaje-prijema za radio-uređaje,

$I_{\text {pred }}$-struja predaje,

$f_{\text {pred }}-$ faktor korekcije potrošnje kapaciteta za $I_{\text {pred }}$

$I_{p r i j}$ - struja prijema,

$f_{\text {prij }}$ - faktor korekcije potrošnje kapaciteta za $I_{p r i j}$

Za motorna vozila $A=90$ dana za akumulatore veće od 100 Ah i $A=60$ dana za akumulatore manje od $100 \mathrm{Ah}$;

- raspoloživa električna energija akumulatora za vreme upotrebe:

$$
W_{r}=k W_{i n}=k \sum_{i=1}^{n} C_{i} U_{i n i} \quad[W h]
$$

gde je:

$k$ - faktor smanjenja vrednosti nominalnog kapaciteta:

$k=k_{s t} k_{T} k_{\text {sam }} k_{o d} k_{i}<1$

$k_{s t}$ - koeficijent starosti hemijskog izvora, $k_{T}$ - koeficijent uticaja temperature na hemijski izvor, 
$k_{\text {sam }}$ - koeficijent samopražnjenja hemijskog izvora,

$k_{o d}$ - koeficijent održavanja hemijskog izvora,

$k_{i}$ - koeficijent uticaja struje pražnjenja veće od normalne.

Prema iskustvenim podacima vrednost $k$ kreće se u granicama od 0,7 do 0,85 , odnosno, usvaja se:

$-k=0,85$ za olovne akumulatore,

$-k=0,70$ za alkalne akumulatore;

- ukupna struja punjenja svih akumula-

tora, propisana prema vrsti, tipu i raspoloživom vremenu punjenja:

$I_{p}=\sum_{i=1}^{n} I_{p i}[\mathrm{~A}]$ danu rata:

- ukupna dnevna struja punjenja po

$$
\begin{aligned}
I_{d}= & \sum_{i=1}^{n} \frac{W_{d i}}{W_{p i}}[\mathrm{~A}] \\
& - \text { raspoloživo vreme za punjenje: }
\end{aligned}
$$

$t_{p}=t_{z}-t_{r a z}-t_{p r i}-t_{d}$

gde je:

$t_{z}$ - vreme zadržavanja StTOd bez premeštanja,

$t_{r a z}$ - vreme razvijanja - svijanja StTOd

$t_{\text {pri }}$ - vreme pripreme izvora za punjenje

$(0,5 \mathrm{~h})$

$t_{d}$ - vreme dotura napunjenih akumulatora,

- snaga elektroagregata za dnevno punjenje akumulatora:

$P_{d}=f a b \frac{W_{d} g W_{p}}{\eta_{p} t_{p}}$ gde je:

$f$-koeficijent za uvećanje el. energije zbog ojačanja (zadaje se u granicama $1-1,40$ ),

$\eta_{p}$ - stepen iskorišćenja punjača $\left(\eta_{\mathrm{p}}=0,9\right.$

$-0,95$ za jedan punjač i $\eta_{\mathrm{p}}=0,85$ za 3 punjača),

$a$ - faktor povećanja snage elektroagregata u slučaju korišćenja brzih punjača (1 do 2), $b$ - koeficijent jednovremenosti korišćenja svih punjača $(0,85$ do 1$)$,

$g$ - verovatnoća nepovratnih gubitaka akumulatora, (usvaja se 0,005),

$t_{p}$ - raspoloživo vreme za punjenje akumulatora;

- snaga naizmeničnih elektroagregata podrazumeva snagu potrebnu za napajanje potrošača $u$ pokretnim radionicama u StTOd:

$P=\sum_{j=1}^{l} i_{j} P_{i n j}$

gde je:

$i_{j}$ - faktor jednovremenog korišćenja svih potrošača električne energije na $i$-tom TMS,

$P_{i n j}$ - instalisana snaga električne energije svih potrošača na $i$-tom tehničkom sredstvu,

$j=1,2, \ldots .1$, broj grupa tehničkih sredstava sa ugrađenim potrošačima naizmenične električne energije;

- koeficijent gotovosti:

$$
K_{g}=\frac{1}{1+\frac{\tau}{T}}=\frac{T}{T+\tau}
$$

gde je:

$T$ - ukupno vreme rada radnog i rezervnog kompleta, 
$\tau$ - vreme koje je uređaj bio bez izvora napajanja.

Ako je $K_{g}=1$ (što se želi postići) onda mora biti $\tau=0$; njenju:

- broj akumulatora na dnevnom pu-

$N_{d}=n \frac{t_{r}\left(n_{k}+n_{r}\right)}{A}$

gde je:

$n$-ukupan broj TMS,

$n_{k}-$ broj akumulatora u radnom kompletu,

$n_{r}$ - broj akumulatora u rezervnom kompletu,

$A$ - stvarna autonomija (sa radnim i rezervnim kompletom),

$t_{r}$ - neprekidno angažovanje sredstava $\mathrm{u}$ operaciji (prihvata se $16 \mathrm{~h}$ ).

Za poznavanje stanja hemijskih izvora struje i za preduzimanje mera za njihovo dovođenje u stanje kada mogu obezbediti koeficijent gotovosti $\mathrm{Kg}=1$ za sva sredstva koja su na upotrebi u jedinici, potrebno je da budu dostupni prvenstveno sledeći podaci:

$P_{d}$ - snaga elektroagregata za dnevno punjenje akumulatora,

$W_{d}$ - električna energija punjenja po danu rata,

$n_{d}$ - broj akumulatora na dnevnom punjenju;

- dnevne potrebe pogonskog goriva za elektroagregate:

$P G_{d}=\sum_{s=1}^{l} N_{s}(d / r)_{s}(p / r)_{s} \quad[$ lit $]$

gde je:

$s=1,2, \ldots t$, broj vrsta elektroagregata sa različitom dnevnom potrošnjom, $N_{s}$ - broj elektroagregata $s$-te vrste, $(d / r)_{s}$ - kriterijum za dnevnu potrošnju pogonskog goriva elektroagregata $s$-te vrste,

$(p / r)_{s}$ - punjenje rezervoara elektroagregata $s$-te vrste.

Dnevne potrebe pogonskog goriva izražavaju se posebno za motorni benzin i za dizel gorivo. U odnosu na dnevne potrebe pogonskog goriva, $\mathrm{u}$ određenom procentu izračunavaju se i količine ostalih pogonskih sredstava po posebnom kriterijumu.

\section{Proračun rezervi akumulatora}

S obzirom na veliki broj olovnih akumulatora u svim ZTJ i nepoznavanja njihovog trenutnog stanja, veoma je teško predvideti mogućnost otkaza i dinamiku zamene. Uzimajući u obzir prosečan vek olovnih akumulatora od 3 godine za formirane i 5 godina za suvopunjene, procenjuju se godišnje potrebe za zamenom od $1 / 5$ do $1 / 3$ postojećih akumulatora (u prvoj godini realni su i veći otkazi).

Pri planiranju rezervi alkalnih akumulatora potrebno je, pored zanavljanja ,isluženih“ akumulatora, uzeti u obzir i postizanje koeficijenta gotovosti $\mathrm{K}_{\mathrm{g}}=1$.

Potpunije sagledavanje rezervi moguće je pomoću „verovatnosnog modela“ određivanja dinamike kretanja rezervi za akumulatore $\mathrm{u}$ eksploataciji.

Akumulatori se, pri matematičkoj formulaciji problema, razmatraju kao nepopravljivi uređaji koji se mogu naći u samo dva stanja - ispravnom i neispravnom.

U praksi je dominantan normalni otkaz (postepeni otkaz) zbog gubitka kapaciteta, porasta unutrašnjeg otpora i povećanja samopražnjenja u odnosu na iznenadne otkaze, kao posledice nepravilnog rukovanja i nepredviđenih događaja, a koji su sastavni deo prakse. 
Normalni otkazi imaju zakonomerni karakter, pa se njihove pojave, sa određenom verovatnoćom, mogu unapred predvideti.

- verovatnoća bezotkaznog rada akumulatora, tj. verovatnoća da za date uslove eksploatacije i unapred zadato vreme $T$ neće doći do otkaza, $p(t)=P(T>t)$, odnosno, statistička veličina $\mathrm{p}^{*}(\mathrm{t})$ određuje se prema izrazu:

$p^{*}(t)=\frac{N-m(t)}{N}=1-\frac{m(t)}{N} \quad m(t) \leq N$

gde je:

$N$ - ukupan broj rashodovanih akumulatora, $m(t)$ - broj rashodovanih akumulatora $\mathrm{u}$ vremenu $t$

- verovatnoća otkaza za vreme $t$ definisana je sa $q(t)=P(T \leq t)$ i predstavlja integralnu zakonitost raspodele, odnosno kumulativnu relativnu učestalost otkaza.

Statistička veličina $q^{*}(t)$, određuje se prema izrazu:

$q^{*}(t)=1-p^{*}(t)=\frac{m(t)}{N} \quad m(t) \leq N$

Učestalost otkaza koja predstavlja brzinu „opadanja“" pouzdanosti akumulatora

$f(t)=-\frac{d p}{d t}$ ili

$f *(t)=\frac{m(\Delta t)}{N}$

gde je $m(\Delta t)$ broj rashodovanih akumulatora $u$ jedinici vremena;
- intenzitet otkaza predstavlja se odnosom:

$$
\lambda(t)=\frac{f(t)}{p(t)}
$$

Statički $\lambda^{*}(t)$ predstavlja broj rashodovanih akumulatora $u$ jedinici vremena $m(\Delta t)$ prema ukupnom broju akumulatora koji do tog trenutka još nisu rashodovani:

$$
\begin{aligned}
\lambda *(t) & =\frac{m(\Delta t)}{N-m(\Delta t)} \\
& - \text { statističko srednje vreme do otkaza, }
\end{aligned}
$$
odnosno, srednji vek trajanja, određuje se prema izrazu:

$$
T_{s r}=\frac{1}{n}\left(t_{1}+t_{2}+\ldots+t_{n}\right)=\frac{1}{n} \sum_{i=1}^{n} t_{i}
$$

$t_{i}$ je vek trajanja $i$-tog akumulatora iz posmatranog skupa od $n$ vrsta, a određuje se prema podacima iz kartona rashodovanog akumulatora, na osnovu podataka o datumu formiranja i datumu rashodovanja.

$\mathrm{Na}$ osnovu kriterijuma da se olovni akumulator može upotrebljavati sve dok mu je kapacitet za $70 \%$ veći od nazivnog, akumulatori su svrstani u pet kategorija (tabela).

Ukoliko se u sistemu ne vrši nikakva zamena, a s obzirom na pet usvojenih starosnih kategorija akumulatora,

Kategorije akumulatora

\begin{tabular}{|l|r|r|r|r|r|r|}
\hline $\begin{array}{c}\text { Kvalitet } \\
\text { akumulatora }\end{array}$ & Kategorija & Kapacitet & $\begin{array}{r}\text { Vreme u } \\
\text { eksploataciji }\end{array}$ & Kol. & $\begin{array}{c}\text { Verovatnoća } \\
\text { bezotkaznog rada }\end{array}$ & $\begin{array}{c}\text { \% gubitka radne } \\
\text { sposobnosti }\end{array}$ \\
\hline Odličan & I & $0,9 \mathrm{Cn}$ & do 2 god. & $\mathrm{N}_{1}$ & $0,92-0,99(0,95)$ & $0-25$ \\
\hline Vrlo dobar & II & $0,8-0,9 \mathrm{Cn}$ & $2-3$ god. & $\mathrm{N}_{2}$ & $0,71-0,91(0,80)$ & $25-50$ \\
\hline Dobar & III & $0,75-0,8 \mathrm{Cn}$ & $3-3,5$ god. & $\mathrm{N}_{3}$ & $0,46-0,70(0,60)$ & $51-70$ \\
\hline Podnošljiv & IV & $0,70-0,75 \mathrm{Cn}$ & $3,5-4,0$ god. & $\mathrm{N}_{4}$ & $0,20-0,45(0,35)$ & $71-90$ \\
\hline Za rashod & V & $0-0,70 \mathrm{Cn}$ & $>4$ god. & $\mathrm{N}_{5}$ & $<0,20$ & $>91$ \\
\hline
\end{tabular}


ukupan broj akumulatora u nekom trenutku, određen je izrazom:

$$
N_{0}(t)=\sum_{i=1}^{5} N_{i} p\left(t / t_{i}\right)
$$

gde je $p\left(t / t_{i}\right)$ uslovna verovatnoća da će skup akumulatora, koji su u posmatranom trenutku istrošeni u meri koja odgovara verovatnoći $p\left(t_{i}\right)$, ,preživeti“ još vreme $t$.

Ako je na skupu akumulatora u eksploataciji do trenutka $\tau$ broj zamenjenih akumulatora određen veličinom $r(\tau)$, tada veličina $\delta(\tau)=r(\tau)-r(\tau-1)$ predstavlja broj akumulatora koji su zamenjeni $u$ intervalu $(\tau, \tau-1)$.

Novi akumulatori će se u eksploataciji ponašati po istom zakonu verovatnoće kao i akumulatori koji rade od početnog trenutka, samo će doći do vremenskog pomeranja njihove verovatnoće bezotkaznog rada za $\tau$, odnosno kod njih će se računati $p(t-\tau)$.

Ukoliko se popunjavanje (zamena) akumulatora vrši od trenutka $\tau=1$ do $\tau=t \mathrm{u}$ nekim određenim intervalima ukupan broj ,preživelih“ akumulatora od novih (zamenjenih) biće određen relacijom:

$$
\begin{aligned}
N_{z}(t) & =\sum_{\tau=1}^{t} \delta(\tau) p(t-\tau) \\
& - \text { ukupan broj ,preživelih“ akumu- }
\end{aligned}
$$
latora u sistemu, vodeći računa i o onima koji rade od trenutka $t=0$, dobija se po obrascu:

$$
\begin{aligned}
& N(t)=N_{o}(t)+N_{z}(t)= \\
& =N_{o}(t)+\sum_{\tau=1}^{t} \delta(t) p(t-\tau)
\end{aligned}
$$

Iz ovog izraza može se izračunati i broj akumulatora koje je potrebno obezbediti za zamenu normalno otkazalih akumulatora $\mathrm{u}$ intervalu $t$ :
$\delta(t)=N-N_{o}(t)-\sum_{\tau=1}^{t} \delta(t) p(t-\tau)$

\section{Proračun ljudstva potrebnog za aktiviranje suvopunjenih akumulatora u toku mobilizacije}

Proračun potrebnog broja izvršilaca za aktiviranje suvopunjenih akumulatora i postavljanje na motorna vozila može se empirijski proračunati:

$$
\begin{aligned}
& N_{A A}=\left(\frac{1}{T_{r a d}-1} \sum_{i=1}^{n} T_{A i} Q_{A i}\right) N_{T C}+ \\
& +N_{O A}+N_{P A}+N_{R E}+N_{z r}
\end{aligned}
$$

gde je:

$T_{\text {rad }}$ - trajanje radova u kojem se vrši dekonzervacija motornih vozila $(\mathrm{m} / \mathrm{v})$,

$T_{A i}$ - vreme potrebno za aktiviranje i postavljanje jednog akumulatora na $\mathrm{m} / \mathrm{v}$,

$Q_{A i}$ - broj akumulatora i-te vrste koje je potrebno formirati,

$N_{T C}$ - broj ljudi u tehnološkoj celini koji vrši prenos akumulatora na mesto formiranja i formira akumulatore,

$N_{O A}$ - broj ljudi za odnošenje akumulatora na $\mathrm{m} / \mathrm{v}$,

$N_{P A}$ - broj ljudi za postavljanje akumulatora na $\mathrm{m} / \mathrm{v}$,

$N_{R E}$ - broj rukovodilaca ekipe,

$N_{Z R}$ - broj zamenika rukovodilaca ekipe.

Trajanje radova $\left(T_{\text {rad }}\right)$ računa se po formuli:

$$
T_{r a d}=2 / 3 T_{m o b}-T_{u z b}-T_{u o}
$$

gde je:

$T_{m o b}$-vreme mobilizacije,

$T_{u z b}$ - vreme uzbunjivanja, 
$T_{U O}$ - vreme utovara sredstava ekipe za dekonz. $\mathrm{m} / \mathrm{v}$ i vreme njenog dolaska do $\mathrm{m} / \mathrm{v}$.

\section{Zaključak}

U ovom radu prezentiran je matematički model koji je, jednim delom, zasnovan na empirijskim pokazateljima za proračun i određivanje elektroenergetskog bilansa za bilo koju jedinicu, uz uvažavanje najbitnijih taktičkih i tehničkih parametara. Na osnovu dobijenih rezultata proračuna može se planski pristupiti elektroenergetskom obezbeđenju jedinice.

Poznavanje elektroenergetskog bilansa omogućuje komandovanju bolje praćenje ovog vrlo važnog faktora borbene gotovosti jedinice. Prikazani matematički model podrazumeva i primenu auto- matizacije proračuna i obrade podataka na bilo kom savremenom računaru, a time i kvalitetniju obradu dobijenih rezultata za potrebe odlučivanja po ovoj problematici. Kao problem koji bi trebalo rešavati u daljem periodu opremanja i naoružavanja Vojske, nameće se potreba unifikacije izvora za napajanje, a samim tim i opreme za njihovo održavanje, što bi pojednostavilo rukovanje i osnovno održavanje.

\section{Literatura:}

[1] Memišević, V.; Beoković, M.: Hemijski izvori električne energije, VIZ Beograd, 1983.

[2] Marčetić, M.: Usavršavanje održavanja EIEE, Projektni zadatak, TVA Zagreb.

[3] Milanović, V.: Analiza pouzdanosti EIEE, seminarski rad VTA, 1998

[4] Milanović, V.: Priprema EIEE za eksploataciju u toku mobilizacije, seminarski rad VTA, 2000.

[5] Vuksanović, D.: Elektroenergetsko obezbeđenje oklopne brigade, seminarski rad VTA, 1998. 